\title{
Dye Dependent Regeneration Dynamics in Dye Sensitized Nanocrystalline Solar Cells: Evidence for the Formation of a Ruthenium Bipyridyl Cation/Iodide Intermediate
}

\author{
John N. Clifford, ${ }^{\dagger, »}$ Emilio Palomares, ${ }^{\dagger}$, Md. K. Nazeeruddin," M. Grätzel," and \\ James R. Durrant*, \\ Department of Chemistry, Imperial College London, Exhibition Road, SW7 2AZ London, U.K., Laboratory for \\ Photonics and Interfaces, Institute of Physical Chemistry, Swiss Federal Institute of Technology, CH-1015 \\ Lausanne, Switzerland, Department of Chemistry, Katholieke Universiteit Leuven, Celestijnenlaan 200F, \\ B-3001 Heverlee, Belgium, and Institut Català d'Investigació Química, Avda. Països Catalans, 16, Tarragona \\ C.P. 43007, Tarragona, Spain
}

Received: November 10, 2006; In Final Form: February 15, 2007

\begin{abstract}
We report a transient absorption study of the kinetics of re-reduction of ruthenium bipyridyl dye cations adsorbed to nanocrystalline $\mathrm{TiO}_{2}$ films by iodide ions, employing a series of $\mathrm{Ru}^{\mathrm{II}}(\mathrm{dcbpy})_{2} \mathrm{X}$ dyes, where dcpby $=4,4^{\prime}$-dicarboxy-2,2'-bipyridyl and $\mathrm{X}=(\mathrm{NCS})_{2},(\mathrm{CN})_{2}$, DTC (diethyldithiocarbamate), and $\mathrm{Cl}_{2}$. The data indicate that this re-reduction (or 'regeneration') reaction proceeds via a transient (dye ${ }^{+}-$iodide) intermediate complex formed by reaction of photogenerated dye cations with one iodide ion. The subsequent reaction of this complex with a second iodide ion, forming $\mathrm{I}_{2}^{-}$, is shown to be the kinetically and thermodynamically limiting step in the overall regeneration reaction. The implications of this reaction scheme for the function of dye sensitized photoelectrochemical cells are discussed, considering in particular the high photovoltaic efficiencies obtained for such devices employing such ruthenium bipyridyl senstiser dyes in combination with iodide/tri-iodide based redox electrolytes.
\end{abstract}

\section{Introduction}

Considerable attention has focused recently on the use of dye sensitized solar cells based on nanoporous titania films as viable alternatives to current solar cell technology. ${ }^{1}$ To date the highest energy conversion efficiencies have been reported for devices employing ruthenium bipyridyl sensitizer dyes in combination with an iodide/triiodide $\left(\mathrm{I}^{-} / \mathrm{I}_{3}{ }^{-}\right)$redox electrolyte. ${ }^{1}$ Attempts to replace the iodide/triodide redox couple with a range of alternatives have only had limited success to date. ${ }^{1-3}$ The success of this redox couple has generally been attributed to its slow exchange current density on $\mathrm{TiO}_{2}$ surfaces, minimizing unwanted interfacial charge recombination losses ('the dark current'). Less attention has been placed upon the remarkable efficiency of this redox couple in re-reducing the oxidized dye, responsible for regenerating the dye ground state in this device under illumination. ${ }^{4,5}$ Previous studies of the reductive quenching of metal to ligand charge transfer excited states of organometallic dyes by iodide ions have found this process to be inefficient, attributed to the unfavorable energetics for the one electron oxidation of iodide. ${ }^{6,7} \mathrm{We}$ report herein the observation of a specific complex between ruthenium bipyridyl cations and iodide ions generated as a intermediate species in the regeneration process, and propose that the formation of this intermediate may be a key factor underlying the efficiency of ruthenium bipyridyl-iodide/triiodide based dye sensitized solar cells.

In dye sensitized solar cells, the kinetics of electron transfer reactions at the metal oxide/sensitizer dye/electrolyte interfaces are critical to the device efficiency. Of the various competing

\footnotetext{
* Corresponding author. E-mail: j.durrant@imperial.ac.uk.

Imperial College London.

$\doteqdot$ Katholieke Universiteit Leuven.

§ Institut Català d'Investigació Química.

" Swiss Federal Institute of Technology.
}

reactions, a key competition arises between charge recombination of electrons in the film with dye cations on the $\mathrm{TiO}_{2}$ surface $\left(k_{\mathrm{cr}}\right)$ and the regeneration of neutral dye species by the redox couple $\left(k_{\text {reg }}\right)$, as illustrated in Scheme 1. This kinetic competition can be of particular importance for more solid state (and therefore more viscous) electrolytes such as polymer electrolytes, polymer gel electrolytes, and ionic liquids attracting increasing interest for technological device applications. ${ }^{8,9}$ The charge recombination reaction $k_{\mathrm{cr}}$ has been studied extensively by our group and others and has been shown to occur in the micro- to millisecond time domain. ${ }^{10-12}$ However, rather less attention has been focused on the regeneration reaction, and more importantly, on the parameters affecting its competition with charge recombination. The kinetics of the regeneration reaction have been the subject of several studies. ${ }^{13-17}$ Of particular relevance, we have shown that when employing $\mathrm{TiO}_{2}$ films sensitized with $\mathrm{Ru}(\mathrm{dcbpy})_{2}(\mathrm{NCS})_{2}$ in the presence of iodide/ triiodide $\left(\mathrm{I}^{-} / \mathrm{I}_{3}{ }^{-}\right)$redox couple, the regeneration reaction proceeds via the formation of $\mathrm{I}_{2}{ }^{-}{ }^{18}$

$$
\text { dye }{ }^{+}+2 \mathrm{I}^{-} \rightarrow \text { dye }+\mathrm{I}_{2}^{-}
$$

$\mathrm{I}_{2}{ }^{-}$then dismutates to yield iodide and triiodide:

$$
2 \mathrm{I}_{2}^{-} \rightarrow \mathrm{I}^{-}+\mathrm{I}_{3}^{-}
$$

Although the above equations may represent the stoichiometry of the regeneration reaction, the mechanism involving the regeneration of the neutral dye species from dye cations (eq 1 above) is unknown and has indeed been a topic of several discussions. ${ }^{18-22}$ The fact that the $\mathrm{I}^{-} / \mathrm{I}_{3}{ }^{-}$system is a two-electron couple suggests the regeneration reaction, eq 1 , may proceed through one or more intermediate states. Several studies have 
SCHEME 1: Illustration of Interfacial Electron Transfer Pathways, Showing the Kinetic Competition between the Dye Regeneration Reaction $\left(k_{\mathrm{reg}}\right)$ and Charge Recombination $\left(k_{\mathrm{cr}}\right)$

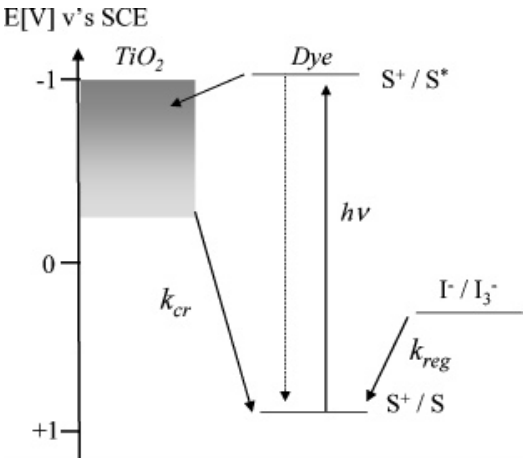

previously discussed possible complex formation between iodide species and sensitizer dyes in either their neutral or oxidized states. ${ }^{13,23,24}$ In particular, Walter and Elliott have reported optical absorbance and X-ray structural data for the formation of a charge transfer complex between iodide and a chromium(III) analogue of the Ru(dcbpy $)_{2}(\mathrm{NCS})_{2}$ dye cation. ${ }^{25}$ However, direct evidence for the transient formation of such intermediates in the regeneration reaction has not been clearly reported to date. In this paper we address this issue and present data which strongly advocates the formation of an intermediate species between the $\mathrm{I}^{-} / \mathrm{I}_{3}{ }^{-}$redox couple and dye cations. It is pertinent to note that the iodide/dye intermediate complex reported herein is not observed with the dye ground state, but it is rather formed transiently following photogeneration of the dye cation species.

\section{Materials and Methods}

This study employs four ruthenium polypyridyl sensitizer dyes, $1 \mathrm{Ru}(\text { dcbpy })_{2}(\mathrm{NCS})_{2}, 2 \mathrm{Ru}(\mathrm{dcbpy})_{2}(\mathrm{CN})_{2}, 3 \mathrm{Ru}(\mathrm{dcbpy})_{2-}$ $\left[\mathrm{S}_{2} \mathrm{CHN}\left(\mathrm{C}_{2} \mathrm{H}_{5}\right)_{2}\right]$ (hereafter referred to as $\mathrm{Ru}(\mathrm{dcbpy})_{2} \mathrm{DTC}$ where DTC is diethyldithiocarbamate), and $4 \mathrm{Ru}(\mathrm{dcbpy})_{2} \mathrm{Cl}_{2}$. The structures of 1-4 are illustrated in Scheme 2. The ground state oxidation potentials for these dyes are also given in Scheme 2, as determined in previous studies. ${ }^{26,27}$ The synthesis of $\mathbf{1 - 4}$ has been reported previously. ${ }^{28}$ The charge recombination dynamics of these sensitizers on nanocrystalline $\mathrm{TiO}_{2}$ has also already been discussed in detail by us elsewhere. ${ }^{26}$ Nanocrystalline $\mathrm{TiO}_{2}$ film preparation and subsequent film dye sensitization procedures were carried out as described previously. ${ }^{29}$ For all four dyes, the carboxylated bipyridine groups were initially fully protonated.

Transient absorption spectroscopy was used to monitor charge recombination dynamics following optical excitation of dye sensitized $\mathrm{TiO}_{2}$ films, and details of the apparatus employed have been given previously. ${ }^{30}$ The decay kinetics were recorded in $0.15 \mathrm{M}$ propylene carbonate solutions of redox active (LiI) and redox inactive $\left(\mathrm{LiClO}_{4}\right)$ electrolytes unless otherwise stated. The redox inactive electrolyte consisted of $\mathrm{LiClO}_{4}$ so that for measurements recorded in the presence and absence of the iodide electron donor, the concentration of $\mathrm{Li}^{+}$remains the same. $\mathrm{Li}^{+}$ is expected to modulate the surface charge of the $\mathrm{TiO}_{2}$ and therefore affect the electron injection yield. Equal concentrations of $\mathrm{Li}^{+}$ensure that the injection yield remains constant during all measurements, as has been demonstrated previously. ${ }^{18}$

All experiments were conducted at room temperature. Experiments employed low-intensity excitation pulses $\left(20 \mu \mathrm{J} \mathrm{cm}^{-2}\right)$ at $500 \mathrm{~nm}$. At this excitation wavelength the optical density of all films employed was $\sim 0.3$, resulting in equal excitation densities for both sensitizer dyes ( $<1$ excited dyes/nanoparticle). Recombination dynamics were monitored following the decay of the photoinduced absorption of the $\mathrm{e}^{-} \mathrm{TiO}_{2} / \mathrm{dye}^{+}$state observed following photoinduced charge separation initiated by the pulsed laser excitation.

Incident photon to current efficiency (IPCE) data were collected with sandwich type dye sensitized solar cells, employing $12 \mu \mathrm{m} \mathrm{TiO}$ films pretreated with $\mathrm{TiCl}_{4}$ solution. Films were sensitized for $15 \mathrm{~h}$ in $3 \times 10^{-4} \mathrm{M}$ dye solution in dry ethanol. Device were fabricated using an electrolyte containing $0.6 \mathrm{M}$ of dimethyl-propyl imidazolium iodide (BMII), $0.1 \mathrm{M}$ of LiI, $0.1 \mathrm{M}$ of $\mathrm{I}_{2}$, and $0.5 \mathrm{M}$ tert-butylpyridine in a mixture of acetonitrile and methoxypropionitrile (volume ratio: 70:30).

\section{Results}

Optical excitation of the sensitizer Ru(dcbpy $)_{2}(\mathrm{NCS})_{2}$ adsorbed to nanocrystalline $\mathrm{TiO}_{2}$ results in electron injection into the metal oxide, generating the charge separated state (Ru$\left.(\text { dcbpy })_{2}(\mathrm{NCS})_{2}\right)^{+} / \mathrm{e}^{-} \mathrm{TiO}_{2}$. This state is characterized by the appearance of a strong dye cation charge transfer (CT) band centered at around $800 \mathrm{~nm}$ superimposed upon a broader and weaker absorption assigned to $\mathrm{e}^{-} \mathrm{TiO}_{2}$ absorption. The strong dye cation CT transition arises from localization of the dye cation HOMO orbital on the NCS ligands. ${ }^{26,31,32}$ For the other sensitizer dyes $\mathbf{2}-\mathbf{4}$, optical excitation also results in efficient electron injection into the $\mathrm{TiO}_{2}$ film, resulting in analogous, long-lived charged separated states. ${ }^{26}$ However for these dyes, the cation HOMO orbitals are more metal centered, and therefore strong $\mathrm{CT}$ absorption is no longer expected. The absence of a CT band for the cation state of these dyes is crucial to our observation of the intermediate dye $^{+} /$iodide species as will be discussed below.

Figure 1 shows transient absorption kinetic data for $\mathrm{TiO}_{2}$ films sensitized with the four sensitizer dyes in a redox inactive

\section{SCHEME 2: Structures of Dyes 1-4}

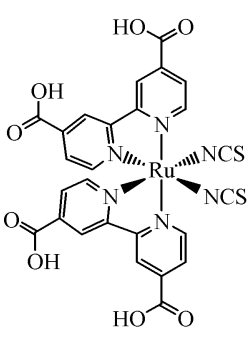

1

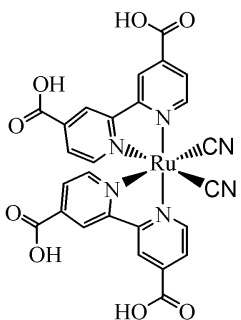

2

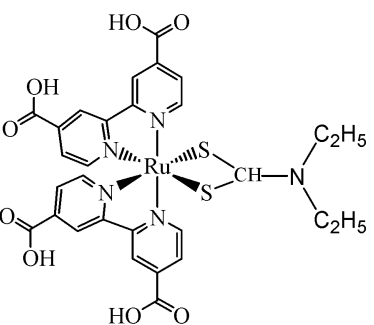

3

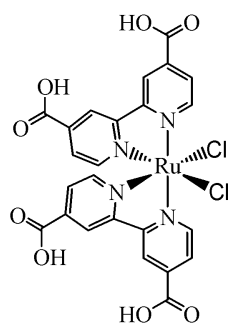

4

${ }^{a}$ 1: $\mathrm{Ru}(\mathrm{dcbpy})_{2}(\mathrm{NCS})_{2}$. 2: $\mathrm{Ru}(\mathrm{dcbpy})_{2}(\mathrm{CN})_{2}$. 3: $\mathrm{Ru}(\mathrm{dcbpy})_{2} \mathrm{DTC}$. 4: $\mathrm{Ru}(\mathrm{dcbpy})_{2} \mathrm{Cl}_{2}$. The $E^{0}\left(D^{+} / D\right)$ ground state oxidation potentials for 1-4 are, respectively, $0.85,1.00,0.80$, and $0.56 \mathrm{~V}$ vs SCE. 


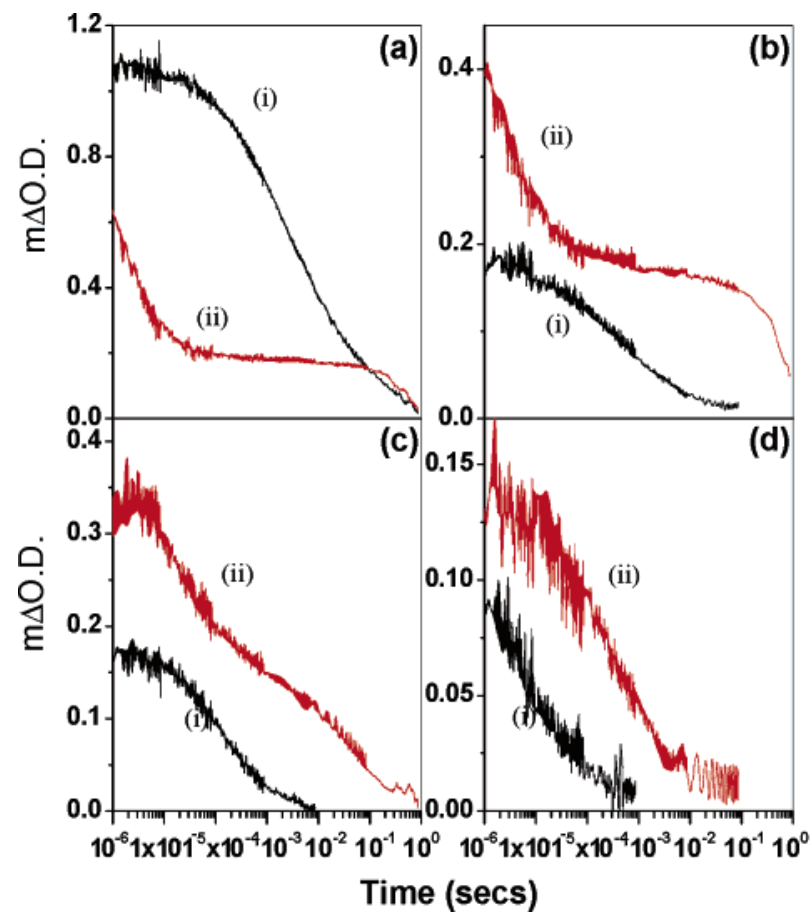

Figure 1. Transient absorption data monitoring charge recombination in nanocrystalline $\mathrm{TiO}_{2}$ films sensitized with dyes $\mathbf{1} \mathrm{Ru}(\mathrm{dcbpy})_{2}(\mathrm{NCS})_{2}$ (a), $2 \mathrm{Ru}(\mathrm{dcbpy})_{2}(\mathrm{CN})_{2}$ (b), $3 \mathrm{Ru}$ (dcbpy) ${ }_{2} \mathrm{DTC}$ (c), and $4 \mathrm{Ru}(\mathrm{dcbpy})_{2} \mathrm{Cl}_{2}$ (d) in $0.15 \mathrm{M} \mathrm{LiClO}_{4}$ in propylene carbonate (black, i) and $0.15 \mathrm{M} \mathrm{LiI}$ in propylene carbonate (red, ii). Kinetics were monitored at $800 \mathrm{~nm}$ following optical excitation at $500 \mathrm{~nm}$ employing matched densities of absorbed photons.

electrolyte, $0.15 \mathrm{M} \mathrm{LiClO}_{4}$, and in a redox active electrolyte, $0.15 \mathrm{M}$ LiI. Transient data were collected at a probe wavelength of $800 \mathrm{~nm}$, monitoring photoinduced absorption of both dye cations and injected electrons. As expected, the transient signal for the $\mathrm{Ru}(\mathrm{dcbpy})_{2}(\mathrm{NCS})_{2}$ sensitized film is approximately an order of magnitude larger than that observed for films sensitized by the other sensitizer dyes, consistent with the strong LMCT absorption of the $\mathrm{Ru}(\mathrm{dcbpy})_{2}(\mathrm{NCS})_{2}$ dye cation at this wavelength. In $0.15 \mathrm{M} \mathrm{LiClO}_{4}$, the transient absorption signal observed for all four sensitizers exhibit stretched exponential decay dynamics typical of the kinetics associated with charge recombination for these dyes on nanocrystalline $\mathrm{TiO}_{2}$, as we have shown previously. ${ }^{26}$ The half-time, $t_{50 \%}$, of the decay dynamics are dye dependent, ranging from $<10 \mu$ s for $\mathrm{Ru}-$ $(\text { dcbpy })_{2} \mathrm{Cl}_{2}$ to $2.9 \mathrm{~ms}$ for $\mathrm{Ru}(\mathrm{dcbpy})_{2}(\mathrm{NCS})_{2}$. As we have discussed in detail elsewhere, this dependence derives from variations in the spatial separation of the dye cation HOMO orbital from the $\mathrm{TiO}_{2}$ surface, with the $\mathrm{Ru}(\mathrm{dcbpy})_{2}(\mathrm{NCS})_{2}$ exhibiting the slowest recombination dynamics due to cation localization onto the NCS ligands. ${ }^{26}$ The transient absorption data obtained for the $\mathrm{Ru}(\mathrm{dcbpy})_{2}(\mathrm{NCS})_{2}$ sensitized film in the presence of LiI agrees with previously reported data $^{18}$ in which biphasic behavior is apparent: (1) a fast phase involving quenching of the dye cation signal and assigned to the reduction of $\left[\mathrm{Ru}(\mathrm{dcbpy})_{2}(\mathrm{NCS})_{2}\right]^{+}$by iodide forming $\mathrm{I}_{2}{ }^{-}$species (eq 1); and (2) a slower phase assigned to long-lived $\mathrm{I}_{2}{ }^{-}$and $\mathrm{e}^{-} \mathrm{TiO}_{2}$, with the decay of this signal being assigned the $\mathrm{I}_{2}{ }^{-}$dismutation reaction (eq 2) and interfacial charge recombination of $\mathrm{e}^{-} \mathrm{TiO}_{2}$ with the redox couple. The fast phase has a half-time $t_{50 \%}$ of $\sim 1 \mu \mathrm{s}$, which is over a thousand times faster than the $t_{50 \%}$ for recombination measured in $\mathrm{LiClO}_{4}$. Detailed spectral assignments of these transients, based upon observations of dye ground state bleach $\left(\lambda_{\max } \sim\right.$ $540 \mathrm{~nm})$, dye cation absorption $\left(\lambda_{\max } \sim 800 \mathrm{~nm}\right)$, and $\mathrm{I}_{2}{ }^{-}$

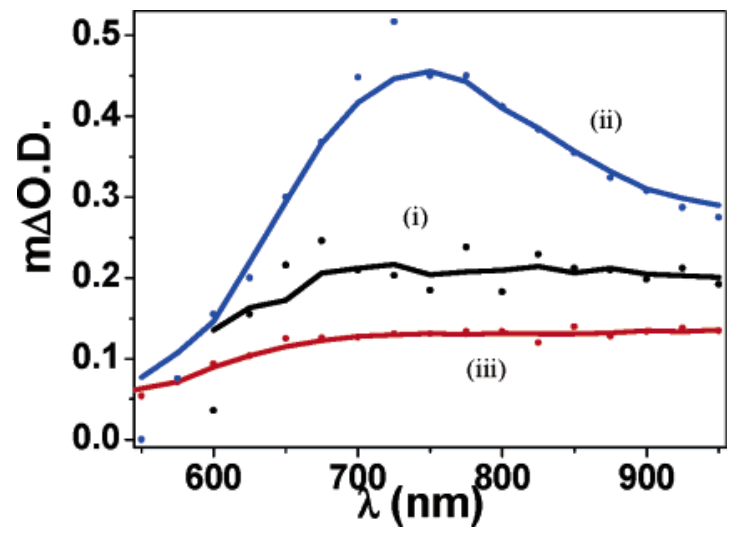

Figure 2. Difference absorption spectra of nanocrystalline $\mathrm{TiO}_{2}$ films sensitized with $2 \mathrm{Ru}(\mathrm{dcbpy})_{2}(\mathrm{CN})_{2}$ (i) in $0.15 \mathrm{M} \mathrm{LiClO}_{4}$ in propylene carbonate at $4 \mu \mathrm{s}$ (black dot) and in $0.15 \mathrm{M} \mathrm{LiI}$ in propylene carbonate at (ii) $4 \mu$ s (blue dot) and at (iii) $10 \mathrm{~ms}$ (red dot). The spectra were recorded after excitation at $500 \mathrm{~nm}$.

absorption $\left(\lambda_{\max } \sim 750\right.$ and $\left.<400 \mathrm{~nm}\right)$, have been reported previously ${ }^{18}$ and are further detailed, with additional spectra, in the Supporting Information.

The transient absorption data obtained for the $\mathrm{Ru}(\mathrm{dcbpy})_{2^{-}}$ $(\mathrm{CN})_{2}$ sensitized film in the presence of LiI also displays a biphasic behavior analogous to that observed for the $\mathrm{Ru}(\mathrm{dcbpy})_{2^{-}}$ $(\mathrm{NCS})_{2}$ sensitized film. However for this sensitizer a large increase is observed in the magnitude of the initial transient signal in the presence of the iodide electrolyte, with the amplitude of the initial signal (time delay $\sim 500 \mathrm{~ns}$ ) being more than twice that observed for the same sample under the same conditions in the $\mathrm{LiClO}_{4}$ control electrolyte. The origin of this increase in signal magnitude was further investigated by recording the initial $(\sim 1 \mu \mathrm{s})$ absorption difference spectra recorded for $\mathrm{Ru}(\mathrm{dcbpy})_{2}(\mathrm{CN})_{2}$ sensitized films in $\mathrm{LiClO}_{4}$ and LiI, as illustrated in Figure 2. With the $\mathrm{LiClO}_{4}$ electrolyte, a broad, featureless absorption increase is observed in the red/ near-infrared spectral region, assigned primarily to $\mathrm{e}^{-} \mathrm{TiO}_{2}$ absorption. In contrast, the absorption difference spectrum recorded in the presence of $\mathrm{LiI}$ at the same time displays a strong absorption band with a maximum at $\sim 700 \mathrm{~nm}$ analogous to the LMCT transition observed for the Ru(dcbpy $)_{2}(\mathrm{NCS})_{2}$ cation. This $1 \mu$ s spectrum continues to exhibit a clear dye ground state bleach (see Supporting Information, Figure S2) and can therefore not be assigned to the rapid (sub-microsecond) formation of $\mathrm{I}_{2}{ }^{-}$species. Figure 2 also shows the absorption difference spectrum recorded for this sample in LiI at a longer time (10 $\mathrm{ms})$. This spectrum is also relatively featureless and is assigned, as previously, ${ }^{18}$ to absorption of $\mathrm{I}_{2}^{-}$and $\mathrm{e}^{-}{ }_{\mathrm{TiO}}$ species generated by the interfacial charge separation processes (electron injection and dye regeneration) (see also Figure S1, Supporting Information).

The origin of the increase in initial signal size observed in the presence of $\mathrm{LiI}$ for $\mathrm{Ru}(\mathrm{dcbpy})_{2}(\mathrm{CN})_{2}$ was further addressed by studies as a function of LiI concentration. Figure 3 shows transient absorption data recorded for $\mathrm{Ru}(\mathrm{dcbpy})_{2}(\mathrm{CN})_{2}$ sensitized $\mathrm{TiO}_{2}$ film in the presence of $0.15 \mathrm{M} \mathrm{LiClO}_{4}, 0.15 \mathrm{M}$ LiI, and $0.015 \mathrm{M} \mathrm{LiI}$ in propylene carbonate solutions. The data collected at the lower $0.015 \mathrm{M}$ iodide concentrations shows strikingly different kinetics. The initial amplitude (at $\sim 1 \mu \mathrm{s}$ ) of this signal is now similar to the initial signal size recorded in $0.15 \mathrm{M} \mathrm{LiClO}_{4}$ solution. However, the signal recorded in $0.015 \mathrm{M}$ LiI exhibits a transient increase in amplitude on the microsecond time scale, reaching a maximum at $\sim 5 \mu$ s. It subsequently exhibits the long-lived dynamics 


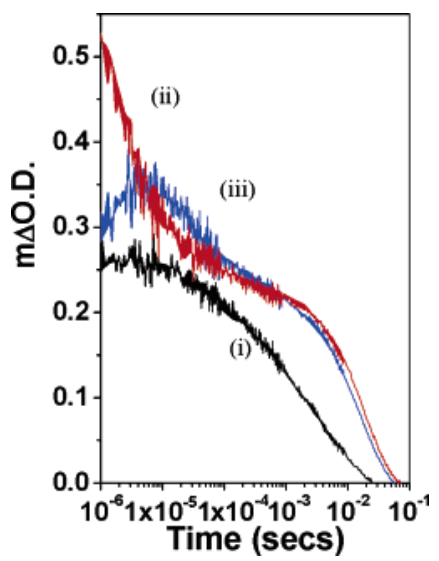

Figure 3. Transient absorption data monitoring charge recombination in nanocrystalline $\mathrm{TiO}_{2}$ films sensitized with $2 \mathrm{Ru}(\mathrm{dcbpy})_{2}(\mathrm{CN})_{2}$ in propylene carbonate solutions containing (i) $0.15 \mathrm{M} \mathrm{LiClO}_{4}$ (black), (ii) $0.15 \mathrm{M} \mathrm{LiI} \mathrm{(red),} \mathrm{and} \mathrm{(iii)} 0.015 \mathrm{M}$ LiI (blue). Kinetics were monitored at $800 \mathrm{~nm}$ following optical excitation at $500 \mathrm{~nm}$.

analogous to those observed at the higher $0.15 \mathrm{M}$ iodide concentration.

As we discuss in detail in the following section, the $700 \mathrm{~nm}$ absorption band observed following optical excitation of $\mathrm{Ru}-$ (dcbpy $)_{2}(\mathrm{CN})_{2}$ sensitized films in the presence of LiI can be most easily rationalized in terms of the formation of a dye cation/ iodide complex. Our observation that at low LiI concentrations $(0.015 \mathrm{M})$ the appearance of this absorption band can be kinetically resolved (occurring in a few microseconds) indicates that this complex is not formed with the dye ground state but is only observed following photogeneration of the dye cation. Supporting this conclusion, we note that the ground state UV/ visible spectrum of the dye sensitized films in the presence and absence of iodide were indistinguishable, consistent with negligible interactions between iodide and the dye ground state.

We now turn to consideration of the transient absorption data observed in the presence of $\mathrm{LiI}$ for $\mathrm{TiO}_{2}$ films sensitized with the two remaining dyes $\mathrm{Ru}(\mathrm{dcbpy})_{2} \mathrm{DTC}$ and $\mathrm{Ru}(\mathrm{dcbpy})_{2} \mathrm{Cl}_{2}$, as shown in Figure 1c,d. In both cases the presence of iodide ions results in an increase in the initial transient absorption signal, as observed for the $\mathrm{Ru}(\mathrm{dcbpy})_{2}(\mathrm{CN})_{2}$ dye. The transient absorption decay dynamics for these dyes do not, however, show the clearly biphasic decays observed for the Ru(dcbpy $)_{2}(\mathrm{CN})_{2}$ and Ru(dcbpy $)_{2}(\mathrm{NCS})_{2}$. For Ru(dcbpy $)_{2} \mathrm{DTC}$, the decay dynamics are just discernibly biphasic, but for $\mathrm{Ru}(\mathrm{dcbpy})_{2} \mathrm{Cl}_{2}$ only a single, nonexponential decay phase is observed.

Our observations that the increase in transient absorption signal observed in the presence of iodide ions is dependent upon sensitizer dye and that the kinetics of this absorption increase are dependent upon iodide concentration clearly indicates this signal should be assigned to the reaction of dye cations with iodide. The implications of this assignment are discussed in detail below.

As all experiments were conducted with matched densities of absorbed photons, and assuming unity yields of electron injection for all four dyes, the magnitude of the long-lived absorption transient assigned to $\mathrm{I}_{2}^{-} / \mathrm{e}^{-} \mathrm{TiO}_{2}$ states is a measure of the relative efficiency of the overall regeneration reaction (eq 1). These relative yields, determined from the magnitude of the transient absorption signal at $1 \mathrm{~ms}$, are given in Table 1, alongside the overall reaction free energy estimated from the dye ground state oxidation potentials, and using an $\mathrm{I}^{-} / \mathrm{I}_{3}{ }^{-}$ oxidation potential in acetonitrile of $+0.1 \mathrm{~V}$ vs SCE. Also detailed in Table 1 are optimum incident photon to current
TABLE 1: Comparison of the Half-Times and Yields for the Rate Determining Step of the Dye Regeneration Reaction, Eq 5, Determined from the Transient Absorption Data Reported Here, with Overall Reaction Free Energy for the Regeneration Reaction Determined from Electrochemical Data and Photocurrent Quantum Efficiency Data for Complete Dye Sensitized Solar Cells

\begin{tabular}{llrcc}
\hline \multicolumn{1}{c}{ dye } & $\begin{array}{c}\Delta G^{0}, \\
\mathrm{eV}^{a}\end{array}$ & $\begin{array}{r}\text { regeneration } \\
t_{50 \%}, \mu \mathrm{s}^{b}\end{array}$ & $\begin{array}{r}\text { regeneration } \\
\text { yield, } \%^{c}\end{array}$ & $\begin{array}{r}\text { IPCE, } \\
\%^{d}\end{array}$ \\
\hline $\mathrm{Ru}(\text { dcbpy })_{2}(\mathrm{NCS})_{2}$ & 0.75 & 1 & 100 & 90 \\
$\mathrm{Ru}(\text { dcbpy })_{2}(\mathrm{CN})_{2}$ & 0.9 & 6 & 95 & 85 \\
$\mathrm{Ru}(\text { dcbpy })_{2} \mathrm{DTC}$ & 0.7 & 19 & 82 & 60 \\
$\mathrm{Ru}(\text { dcbpy })_{2} \mathrm{Cl}_{2}$ & 0.46 & $>100$ & $\leq 26$ & 48
\end{tabular}

${ }^{a}$ Determined from the difference between the ground state oxidation potential of each dye and the chemical potential of the $\left(\mathrm{I}^{-} / \mathrm{I}_{3}{ }^{-}\right)$redox couple. ${ }^{b}$ Determined from the half-time of the fast phase of the transient absorption decay dynamics observed in the presence of iodide, assigned to the reaction of $\left[\mathrm{dye}^{+}: \mathrm{I}^{-}\right]$with a second iodide ion, eq $5 .{ }^{c}$ Determined from the magnitude of the transient absorption signal at $800 \mathrm{~nm}$ at a time delay of $1 \mathrm{~ms}$. For $\mathrm{Ru}(\mathrm{dcbpy})_{2} \mathrm{Cl}_{2}$, the regeneration reaction is not kinetically resolved, and this magnitude therefore represents an upper limit for the regeneration yield. ${ }^{d}$ Maximal incident photon to photocurrent quantum efficiencies determined for 'sandwich' type dye sensitized solar cells employing an optimized redox electrolyte, as specified in Materials and Methods.

conversion efficiencies (IPCE) obtained for dye sensitized photoelectochemical solar cells fabricated with these dyes. Note that the IPCE data were collected with an optimized electrolyte including additives (see Materials and Methods) previously shown to improve device performance, therefore a quantitative comparison between transient absorption and device IPCE data is not possible. Nevertheless, it is apparent from Table 1 that there is a reasonable correlation between the relative yield of the regeneration reaction, the regeneration reaction free energy, and device quantum efficiency. The origins of these correlations and their implication for future device optimization will be discussed below.

\section{Discussion}

Regeneration Dynamics for the $R u(d c b p y)_{2}(C N)_{2}$ Dye Cation. We have shown in previous studies that the regeneration reaction leads to the formation of the $\mathrm{I}_{2}{ }^{-}$anion (eq 1). One simple reaction mechanism consistent with this observation involves the reduction of dye cations by $\mathrm{I}^{-}$resulting in the formation of atomic iodine (eq 3):

$$
\text { dye }{ }^{+}+2 \mathrm{I}^{-} \rightarrow \text { dye }+\mathrm{I}^{\bullet}+\mathrm{I}^{-} \rightarrow \text { dye }+\mathrm{I}_{2}^{-}
$$

This mechanism is, however, thermodynamically prohibited due to the redox potential of the atomic iodine/iodide couple $\left(\mathrm{I}^{\circ} / \mathrm{I}^{-}\right)$ being greater ( $1.17 \mathrm{~V}$ vs SCE in water) than the oxidation potential of the ruthenium dyes in this study, as has been discussed previously in the context of reductive quenching of $\mathrm{Ru}(\mathrm{bpy})_{3}$ MLCT excited states. ${ }^{6,7}$ Furthermore, the intermediate state in this mechanism comprises atomic iodine and the dye ground state. This intermediate state would not give rise to the pronounced $700 \mathrm{~nm}$ absorption maximum observed here for the $\mathrm{Ru}(\text { dcbpy })_{2}(\mathrm{CN})_{2}$ dye. We conclude that the regeneration reaction does not proceed by the reaction mechanism described by eq 3 .

Several previous studies have considered the possible influence of dye/iodide complexes upon the regeneration reaction. ${ }^{13,16,23,25,33}$ Pelet $^{13}$ proposed that depending on the particle surface charge of the $\mathrm{TiO}_{2}$, the regeneration reaction may proceed via the formation of a dye/iodide ion pair $\left(\mathrm{dye}^{+} / \mathrm{I}^{-}\right)$. It was further suggested that, in the case of $\left[\mathrm{Ru}(\mathrm{dcbpy})_{2}(\mathrm{NCS})_{2}\right]^{+}$, 
interactions between the sulfur atom on the dye and $\mathrm{I}^{-}$ could play a significant role in the formation of this complex. The formation of a complex between the oxidized dye and $\mathrm{I}^{-}$has also been suggested by Fitzmaurice ${ }^{23}$ during the regeneration of $\left[\mathrm{Ru}(\mathrm{dcbpy})_{3}\right]^{+}$by $\mathrm{I}^{-}$. In both of these studies, however, there was no direct evidence to support such complex formation.

We present here experimental evidence directly showing the formation of an intermediate complex between the oxidized form of the dye and $\mathrm{I}^{-}$. Figure 3 shows that, for $\mathrm{Ru}(\mathrm{dcbpy})_{2}(\mathrm{CN})_{2}$ sensitized $\mathrm{TiO}_{2}$ in $0.015 \mathrm{M} \mathrm{LiI}$, the initial amplitude of the signal $(\sim 1 \mu \mathrm{s})$ is the same as the initial amplitude of the signal in $\mathrm{LiClO}_{4}$. There then follows a rise in the signal amplitude until a maximum is reached at $5 \mu$ s followed by a biphasic decay of this signal. The transient signal at $1 \mu \mathrm{s}$ in both $\mathrm{LiClO}_{4}$ and low concentrations of $\mathrm{LiI}$ is therefore assigned to the state $[\mathrm{Ru}-$ $\left.(\text { dcbpy })_{2}(\mathrm{CN})_{2}\right]^{+} / \mathrm{e}^{-} \mathrm{TiO}_{2}$. The subsequent increase in signal amplitude in the presence of iodide is assigned to formation of an intermediate complex between the dye cation and $\mathrm{I}^{-}$: $\left[\right.$dye $^{+}$, $\mathrm{I}^{-}$]. At higher iodide concentrations, a similar increase in magnitude of the transient absorption signal is observed, although in this case the increased signal is observed to appear immediately $(<500 \mathrm{~ns})$, presumably because of faster kinetics of complex formation due to the higher concentration of $\mathrm{I}^{-}$ present. The intermediate $\left[\mathrm{dye}^{+}, \mathrm{I}^{-}\right]$appears to result in stronger $\mathrm{red} /$ near-infrared absorption than $\left[\mathrm{Ru}(\mathrm{dcbpy})_{2}(\mathrm{CN})_{2}\right]^{+}$, exhibiting a clear absorption maximum at $700 \mathrm{~nm}$ (Figure 2). We tentatively assign this increased oscillator strength to the expected partial charge transfer character of the intermediate, resulting in a strong $\mathrm{CT}$ transition from the iodide moiety to the metal center. This assignment is consistent with our previous observations $^{26}$ that for $\mathrm{Ru}(\mathrm{dcbpy})_{2} \mathrm{X}_{2}$ cations, the strength of this infrared band correlates with increased delocalization of the cation HOMO orbital over the $\mathrm{X}$ ligand. This increased absorption signal subsequently decays to yield a long-lived signal assigned to the state $\mathrm{I}_{2}^{-} / \mathrm{e}^{-} \mathrm{TiO}_{2}$ (observed at $10 \mathrm{~ms}$ in Figure 2) assigned to the reaction of the intermediate $\left[\mathrm{dye}^{+}\right.$, $\mathrm{I}^{-}$] state with a second $\mathrm{I}^{-}$species. This reaction mechanism for the regeneration reaction can therefore be summarized as follows:

$$
\begin{gathered}
\text { dye }^{+}+\mathrm{I}^{-} \rightarrow\left[\text { dye }^{+}, \mathrm{I}^{-}\right] \\
{\left[\text {dye }^{+}, \mathrm{I}^{-}\right]+\mathrm{I}^{-} \rightarrow \text { dye }+\mathrm{I}_{2}^{-}}
\end{gathered}
$$

The kinetic studies shown in Figures 2 and 3 clearly indicate that intermediate formation, eq 4 , is kinetically fast, while the subsequent reaction of the intermediate with a second iodide species, eq 5 , is at least an order of magnitude slower and is indeed the rate determining step of the overall regeneration reaction. As we discuss below, the slower dynamics associated with eq 5 are most probably associated with less favorable thermodynamics of this reaction.

Comparison between the Four Sensitizer Dyes. The increase in amplitude of the initial transient absorption signal in the presence of iodide ions is also observed for the sensitizer dyes $\mathrm{Ru}(\mathrm{dcbpy})_{2} \mathrm{DTC}$ and $\mathrm{Ru}(\mathrm{dcbpy})_{2} \mathrm{Cl}_{2}$, indicating rapid formation of the $\left[\mathrm{dye}^{+}, \mathrm{I}^{-}\right]$intermediate state as observed for the $\mathrm{Ru}(\mathrm{dcbpy})_{2}(\mathrm{CN})_{2}$ dye. It is striking that this increase in signal magnitude in the presence of LiI is not observed for the Ru$(\text { dcbpy })_{2}(\mathrm{NCS})_{2}$ dye. However the great similarity in transient absorption kinetics in the presence of LiI for the Ru(dcbpy $)_{2}-$ $(\mathrm{NCS})_{2}$ and $\mathrm{Ru}(\mathrm{dcbpy})_{2}(\mathrm{CN})_{2}$ dyes (the red traces in Figures $1 \mathrm{a}, \mathrm{b})$ strongly suggests that the regeneration reaction proceeds through the same reaction mechanism for both sensitizer dyes. We attribute the lack of observation of an increase in signal magnitude for $\mathrm{Ru}(\mathrm{dcbpy})_{2}(\mathrm{NCS})_{2}$ in the presence of $\mathrm{I}^{-}$to the fact that the $\mathrm{Ru}(\mathrm{dcbpy})_{2}(\mathrm{NCS})_{2}$ dye cation already displays a strong CT transition due to localization of the cation state on the NCS groups which masks the formation of any CT transition associated with the intermediate $\left[\right.$ dye $\left.^{+}, \mathrm{I}^{-}\right]$.

We thus conclude that for the three sensitizer dyes $\mathrm{Ru}-$ (dcbpy $)_{2}(\mathrm{CN})_{2}, \mathrm{Ru}(\mathrm{dcbpy})_{2} \mathrm{DTC}$, and $\mathrm{Ru}(\mathrm{dcbpy})_{2} \mathrm{Cl}_{2}$ and, by analogy, most probably $\mathrm{Ru}(\mathrm{dcbpy})_{2}(\mathrm{NCS})_{2}$, photogeneration of the dye cation species in the presence of $0.15 \mathrm{M} \mathrm{LiI}$ results in the rapid $(<500 \mathrm{~ns})$ formation of an intermediate species $\left[\mathrm{dye}^{+}\right.$, $\mathrm{I}^{-}$] according to eq 4 above. This time scale is significantly faster than the dye recombination times observed in the absence of iodide ions. We furthermore note that the formation of this intermediate appears to be independent of dye oxidation potential. We therefore conclude that under the experimental conditions employed, the reaction of iodide ions with dye cations to yield the intermediate state $\left[\mathrm{dye}^{+}, \mathrm{I}^{-}\right]$is kinetically fast and thermodynamically favored for all four dyes studied, without significant competition between this first step of the regeneration reaction and the competing charge recombination pathway $k_{\mathrm{cr}}$.

In contrast to this favorable situation for device function concerning eq 4, the efficiency of the second step of the regeneration reaction, eq 5 , appears to be strongly dye dependent. The yield of $\mathrm{I}_{2}{ }^{-}$species is significantly lower for the dyes $\mathrm{Ru}(\text { dcbpy })_{2} \mathrm{DTC}$ and $\mathrm{Ru}(\mathrm{dcbpy})_{2} \mathrm{Cl}_{2}$, as tabulated in Table 1 . These lower yields correlate with the slower reaction dynamics of the $\left[\mathrm{dye}^{+}, \mathrm{I}^{-}\right]$state with iodide ions, observable as the 'fast' decay phase of the transient kinetics, also tabulated in Table 1. We conclude that the second step of the regeneration reaction, eq 5 , is the kinetically and thermodynamically limiting step in the regeneration reaction which determines the overall efficiency of the regeneration reaction.

We note that this second step of the regeneration reaction, the reaction of the intermediate $\left[\mathrm{dye}^{+}, \mathrm{I}^{-}\right]$state with a second $\mathrm{I}^{-}$species, is kinetically in competition with the recombination of $\mathrm{TiO}_{2}$ electrons with this intermediate state, eq 6 :

$$
\left[\text { dye }^{+}, \mathrm{I}^{-}\right]+\mathrm{e}_{\mathrm{TiO}_{2}}^{-} \rightarrow \text { dye }+\mathrm{I}^{-}
$$

This reaction is distinct from the recombination reaction of $\mathrm{TiO}_{2}$ to dye cations observed in the absence of iodide in that the spatial location of the dye cation HOMO orbital in $\left[\right.$ dye ${ }^{+}, \mathrm{I}^{-}$] can be expected to be quite different from dye cation species alone. This situation can be most clearly observed in the data obtained for $\mathrm{Ru}(\mathrm{dcbpy})_{2} \mathrm{Cl}_{2}$, Figure 1d. For this dye, the cation in the absence of iodide is strongly metal centered, resulting in only a small spatial separation of the cation HOMO orbital from the $\mathrm{TiO}_{2}$ surface and therefore fast recombination dynamics $\left(t_{50 \%}\right.$ $<10 \mu \mathrm{s})$. In the presence of iodide, the $\left[\mathrm{dye}^{+}, \mathrm{I}^{-}\right]$absorption decays relatively slowly with a half time of $200 \mu$ s, indicative of an increased spatial separation of the cation orbital from the $\mathrm{TiO}_{2}$ surface, consistent with $\left[\mathrm{dye}^{+}, \mathrm{I}^{-}\right]$complex formation being associated with a partial electron transfer from the iodide to the dye metal center. As such, we note that the low efficiency of the regeneration reaction observed for this dye appears to result not from the faster recombination dynamics of the dye cation with $\mathrm{TiO}_{2}$ electrons observed for this dye but rather from slower kinetics for the second step of regeneration reaction, eq 5 , most probably associated with thermodynamic limitations resulting from relatively weak oxidizing potential of the cation of this dye.

The Identity of the $\left[\mathrm{Dye}^{+}, \mathrm{I}^{-}\right]$Complex. The chemical nature of the $\left[\mathrm{dye}^{+}, \mathrm{I}^{-}\right]$complex proposed above is not at present 
clear, as its short lifetime complicates detailed spectroscopic characterization. There are two main possibilities. It could be a seven-coordinate complex of ruthenium(III) with a covalent $\mathrm{Ru}-\mathrm{I}$ bond. Seven-coordination is well established for a number of complexes of the Fe, Ru, Os series (e.g., in $\mathrm{M}^{\mathrm{I}}\left[\mathrm{Fe}^{\mathrm{III}}\right.$ (EDTA)$\left.\left(\mathrm{H}_{2} \mathrm{O}\right)\right](\mathrm{M}=\mathrm{Li}, \mathrm{Rb}),{ }^{34} \mathrm{Ru}^{\mathrm{IV}}(\mathrm{DMTC})_{3} \mathrm{I}\left(\mathrm{DMTC}=\mathrm{Me}_{2} \mathrm{CNS}_{2}{ }^{-}\right),{ }^{35}$ and $\left.\left[\mathrm{Os}^{\mathrm{IV}}(\mathrm{bpy}) \mathrm{H}_{2}\left(\mathrm{PPh}_{3}\right)_{2}(\mathrm{CO})\right]^{2+36}\right)$. Alternatively, it could be a 1:1 ground state dye ${ }^{+}: \mathrm{I}^{-}$adduct based upon either ion pairing or a specific $\pi$-interaction with the (bpy) ligand, as has been suggested for the $\left[\mathrm{Ru}(\mathrm{bpy})_{2}(\mathrm{deeb})\right]^{2+}: \mathrm{I}^{-}$system $\left(\right.$deeb $=4,4^{\prime}$ $\left(\mathrm{COOCH}_{2} \mathrm{CH}_{3}\right)_{2}-2,2^{\prime}$ byp $) .{ }^{33}$ The formation of a charge transfer interaction between iodide and bipyridine ligands is supported by optical absorbance and structural studies of the iodide complexation with a chromium analogue of the $\mathrm{Ru}(\mathrm{dcbpy})_{2}$ $(\mathrm{NCS})_{2}$ dye cation. We note that the formation of a sevencoordinate complex would be likely to result in significant ligand exchange and consequential dye degradation under continuous illumination, in contrast to the remarkably high turnover numbers reported in for dye sensitized solar cells employing the $\mathrm{Ru}(\mathrm{dcbpy})_{2}(\mathrm{NCS})_{2}$ dye. ${ }^{37}$ The second possibility is in addition more consistent with the high device efficiencies recently reported employing organic sensitizer dyes. ${ }^{38}$ It therefore appears more likely that the complex is essentially a dye ${ }^{+}$: $\mathrm{I}^{-}$adduct based upon ion pairing or specific $\pi$-interactions. We emphasize however that the $\left[\mathrm{dye}^{+}, \mathrm{I}^{-}\right]$complex reported here is a transient species following the dye photo-oxidation process, and that the subsequent reaction of this intermediate with a second $\mathrm{I}^{-}$ion is the thermodynamically and kinetically limiting step.

The assignment of the $\left[\right.$ dye $\left.^{+}, \mathrm{I}^{-}\right]$complex to an dye ${ }^{+}: \mathrm{I}^{-}$ adduct is consistent with our conclusion that the thermodynamics of the reaction of this adduct with iodide (eq 5) are correlated with the ground state oxidation potential of the sensitizer dye. For such an adduct, complexation with iodide may have only a modest influence on the dye cation HOMO orbital and charge density. The correlation between the thermodynamics of eq 5 and dye ground state oxidation potential is apparent from the data in Table 1, with dye with the less positive oxidation potentials (e.g., $\mathrm{Ru}(\mathrm{dcbpy})_{2} \mathrm{Cl}_{2}$ ) exhibiting the slower kinetics and lower yields for iodide reduction of $\left[\mathrm{dye}^{+}, \mathrm{I}^{-}\right]$ complex.

We note that the regeneration reaction mechanism reported here can be regarded as effectively a catalytic mechanism, whereby the formation of the $\left[\mathrm{dye}^{+}, \mathrm{I}^{-}\right]$intermediate avoids the large energetic barrier which inhibits the direct oxidation of one iodide ion to the iodine radical $\mathrm{I} \cdot$. As such, we expect that the formation of such a $\left[\mathrm{dye}^{+}, \mathrm{I}^{-}\right]$intermediate may be critical to the efficiency of the regeneration reaction in dye sensitized solar cells and, as such, a key consideration in the design of new sensitizer dyes for such devices. The ability demonstrated here for $\mathrm{Ru}(\mathrm{dcbpy})_{2} \mathrm{X}$ dyes to achieve this reaction pathway may be a key factor in the remarkably high device efficiencies achieved by this class of sensitizer dyes.

Relevance to Device Function. It is clear from Table 1 that there is a close correlation between the yield of the regeneration reaction determined from transient absorption data and photovoltaic device quantum efficiencies determined from incident photon to current efficiency (IPCE) data. As we discuss above, the yield of the overall regeneration reaction does not appear to be limited by the initial reaction of an iodide species with the dye cation, eq 4 above, which appears to be achieved rapidly with a high yield for all the dyes studied. Rather the overall yield of the regeneration reaction is dependent upon the efficiency of the second step of the reaction mechanism, the subsequent reaction of a second iodide ion with the $\left[\mathrm{dye}^{+}, \mathrm{I}^{-}\right]$ complex, eq 5 above. As such, the chemical nature, energetics, and spatial configuration of this complex may be key considerations for targeting the development of new sensitizer dyes for dye sensitized solar cells.

Acknowledgment. The authors gratefully acknowledge financial support from the EPSRC, including the Supergen programme 'Excitonic Solar Cells' and the CEC project Molycell (No. 502783). E.P. acknowledges the Spanish Ministerio de Educación y Ciencia (MEC) for the Ramon y Cajal Fellowship. Helpful comments from Bill Griffith, Tom Meyer, and Brian O'Regan are gratefully acknowledged.

Supporting Information Available: Transient spectra. This material is available free of charge via the Internet at http:// pubs.acs.org.

\section{References and Notes}

(1) Gratzel, M. Inorg. Chem. 2005, 44, 6841.

(2) Xue, B. F.; Wang, H. X.; Hu, Y. S.; Li, H.; Wang, Z. X.; Meng, Q. B.; Huang, X. J.; Sato, O.; Chen, L. Q.; Fujishima, A. Photochem. Photobiol. Sci. 2004, 3, 918.

(3) Wang, P.; Zakeeruddin, S. M.; Moser, J. E.; Humphry-Baker, R. Gratzel, M. J. Am. Chem. Soc. 2004, 126, 7164.

(4) Thompson, D. W.; Kelly, C. A.; Farzad, F.; Meyer, G. J. Langmuir 1999, 15,650 .

(5) Gregg, B. A.; Pichot, F.; Ferrere, S.; Fields, C. L. J. Phys. Chem. B. 2001, 105, 1422 .

(6) Demas, J. N.; Addington, J. W. J. Am. Chem. Soc. 1976, 98, 5800.

(7) Stanbury, D. M. Adv. Inorg. Chem. 1989, 33, 69.

(8) Bach, U.; Lupo, D.; Comte, P.; Moser, J. E.; Weissortel, F.; Salbeck, J.; Spreitzer, H.; Gratzel, M. Nature 1998, 395, 583.

(9) Hirata, N.; Kroeze, J. E.; Park, T.; Jones, D.; Haque, S. A.; Holmes, A. B.; Durrant, J. R. Chem. Commun. 2006, 535.

(10) Haque, S. A.; Tachibana, Y.; Klug, D. R.; Durrant, J. R. J. Phys. Chem. B. 1998, 102, 1745

(11) Anderson, N. A.; Lian, T. Q. Annu. Rev. Phys. Chem. 2005, 56, 491.

(12) Watson, D. F.; Meyer, G. J. Annu. Rev. Phys. Chem. 2005, 56, 19.

(13) Pelet, S.; Moser, J. E.; Gratzel, M. J. Phys. Chem. B. 2000, 104, 1791.

(14) Fitzmaurice, D. J.; Frei, H. Langmuir 1991, 7, 1129.

(15) Alebbi, M.; Bignozzi, C. A.; Heimer, T. A.; Hasselmann, G. M.; Meyer, G. J. J. Phys. Chem. B. 1998, 102, 7577.

(16) Nasr, C.; Hotchandani, S.; Kamat, P. V. J. Phys. Chem. B. 1998 102, 4944

(17) Myung, N.; Licht, S. J. Electrochem. Soc. 1995, 142, L129.

(18) Montanari, I.; Nelson, J.; Durrant, J. R. J. Phys. Chem. B. 2002 $106,12203$.

(19) Greijer, H.; Lindgren, J.; Hagfeldt, A. J. Phys. Chem. B. 2001, 105, 6314.

(20) Bisquert, J.; Cahen, D.; Hodes, G.; Ruhle, S.; Zaban, A. J. Phys. Chem. B. 2004, 108, 8106.

(21) Fabregat-Santiago, F.; Bisquert, J.; Garcia-Belmonte, G.; Boschloo, G.; Hagfeldt, A. Sol. Energy Mater. 2005, 87, 117.

(22) Cameron, P. J.; Peter, L. M.; Zakeeruddin, S. M.; Gratzel, M. Coord. Chem. Rev. 2004, 248, 1447.

(23) Fitzmaurice, D. J.; Eschle, M.; Frei, H.; Moser, J. J. Phys. Chem. 1993, 97, 3806.

(24) Agrell, H. G.; Lindgren, J.; Hagfeldt, A. J. Photochem. and Photobiol. A. Chemistry 2004, 164, 23.

(25) Walter, B. J.; Elliott, C. M. Inorg. Chem. 2001, 40, 5924.

(26) Clifford, J. N.; Palomares, E.; Nazeeruddin, M. K.; Gratzel, M.; Nelson, J.; Li, X.; Long, N. J.; Durrant, J. R. J. Am. Chem. Soc. 2004, 126, 5225 .

(27) Zakeeruddin, S. M.; Nazeeruddin, M. K.; Humphry-Baker, R.; Gratzel, M.; Shklover, V. Inorg. Chem. 1998, 37, 5251.

(28) Kalyanasundaram, K.; Gratzel, M. Coord. Chem. Rev. 1998, 177 , 347.

(29) Palomares, E.; Clifford, J. N.; Haque, S. A.; Lutz, T.; Durrant, J. R. J. Am. Chem. Soc. 2003, 125, 475.

(30) Green, A. N. M.; Palomares, E.; Haque, S. A.; Kroon, J. M.; Durrant, J. R. J. Phys. Chem. B. 2005, 109, 12525. 
(31) Wenger, B.; Gratzel, M.; Moser, J. E. J. Am. Chem. Soc. 2005, 127,12150 .

(32) Katoh, R.; Furube, A.; Yoshihara, T.; Hara, K.; Fujihashi, G.; Takano, S.; Murata, S.; Arakawa, H.; Tachiya, M. J. Phys. Chem. B. 2004, $108,4818$.

(33) Clark, C. C.; Marton, A.; Meyer, G. J. Inorg. Chem. 2005, 44, 3383. (34) Lind, M. D.; Hamor, M. J.; Hamor, T. A.; Hoard, J. L. Inorg. Chem. 1964, 3,34
(35) Matson, B. M.; Pignolet, L. H. Inorg. Chem. 1977, 16, 488.

(36) Sullivan, B. P.; Lumpkin, R. S.; Meyer, T. J. Inorg. Chem. 1987 $26,1247$.

(37) Hagfeldt, A.; Gratzel, M. Acc. Chem. Res. 2000, 33, 269.

(38) Hara, K.; Kurashige, M.; Ito, S.; Shinpo, A.; Suga, S.; Sayama, K.; Arakawa, H. Chem. Commun. 2003, 252. 